\title{
EFICIÊNCIA DE UTILIZAÇÃO DE MACRONUTRIENTES EM EUCALIPTO POR MÉTODO NÃO DESTRUTIVO ESTIMADOS POR REDES NEURAIS ARTIFICIAIS
}

\author{
MACRONUTRIENTS USE EFFICIENCY IN EUCALYPT BY NON-DESTRUCTIVE METHODS \\ ESTIMATED BY ARTIFICIAL NEURAL NETWORKS
}

\author{
Bruno Oliveira Lafetá ${ }^{1}$ Reynaldo Campos Santana ${ }^{2}$ Gilciano Saraiva Nogueira ${ }^{2}$ \\ Júlio César Lima Neves ${ }^{3}$ Tamires Mousslech Andrade Penido ${ }^{4}$
}

\section{RESUMO}

A Amostragem Não Destrutiva (AND) permite uma caracterização eficiente, simples e segura das propriedades químicas do vegetal, como o Coeficiente de Utilização Biológico (CUB). A associação da AND com a técnica de Redes Neurais Artificiais (RNA) pode ser uma alternativa potencial em substituição às equações de regressão e aos métodos tradicionais de interpolação. Portanto, o presente trabalho objetivou avaliar a eficiência da RNA e da amostragem não destrutiva para estimar a eficiência de uso de nutrientes no tronco. $\mathrm{O}$ experimento foi instalado em blocos ao acaso, sendo estudado, em três blocos, o efeito de cinco espaçamentos de plantio: T1 - 3,0 m x 0,5 m; T2 - 3,0 m x 1,0 m; T3 - 3,0 m x 1,5 m; T4-3,0 m x 2,0 m e T5 - 3,0 m x 3,0 m. Uma árvore-amostra foi abatida para realizar a cubagem rigorosa e quantificar a matéria seca de casca e lenho por unidade experimental, totalizando-se 15 árvores. As árvores-amostras foram pesadas no campo e subamostras de casca e lenho foram coletadas ao longo do fuste para compor uma amostra composta por árvore. Também foi retirada uma amostra simples de cada componente obtidas com auxílio de um formão e martelo na região do $D A P$ nas mesmas árvores-amostras. As amostras foram secas a $65^{\circ} \mathrm{C}$ até peso constante. $\mathrm{O}$ material vegetal foi moído e submetido à análise química. Ajustaramse modelos de regressão e aplicação de RNA para estimação do $\mathrm{CUB}_{\text {Tronco }}$ a partir do $\mathrm{CUB}_{\mathrm{DAP} \text { Casca }} \mathrm{e}$ $\mathrm{CUB}_{\text {DAP Lenho }}$. As RNA apresentaram maior precisão e confiabilidade do que a regressão. A modelagem por redes neurais artificiais utilizando-se apenas uma amostra da casca na região do $D A P$ demonstrou ser adequada para a estimativa do coeficiente de utilização biológico do tronco.

Palavras-chave: CUB; RNA; amostragem não destrutiva; densidade de plantio.

\section{ABSTRACT}

The Non-Destructive Sampling (NDS) provides an efficient, simple and safe characterization of chemical properties of the plant, as the Coefficient of Biological Use (CBU). The association of NDS with the technique of Artificial Neural Networks (ANN) can be a potential alternative to replace the regression equations and the traditional methods of interpolation. Therefore, this work aimed to evaluate the efficiency of ANN and non-destructive sampling for the efficiency of nutrient use in the trunk. The research plot was installed in a randomized block being studied, in three blocks, the effect of five planting spacing: $\mathrm{T} 1-3,0 \mathrm{~m} \times 0,5 \mathrm{~m}$, $\mathrm{T} 2-3,0 \mathrm{~m} \times 1,0 \mathrm{~m}, \mathrm{~T} 3-3,0 \mathrm{~m} \times 1,5 \mathrm{~m}, \mathrm{~T} 4-3,0 \mathrm{~m} \times 2,0 \mathrm{~m}$ e T5-3,0 $\mathrm{m} \times 3,0 \mathrm{~m}$. A sample-tree was felled to

1 Engenheiro Florestal, MSc., Professor de Engenharia Florestal, Instituto Federal de Educação, Ciência e Tecnologia de Minas Gerais, Av. Primeiro de Junho 1043, Centro, CEP 39100-000, São João Evangelista (MG), Brasil. bruno. lafeta@ifmg.edu.br

2 Engenheiro Florestal, Dr., Professor Adjunto do Departamento de Engenharia Florestal, Universidade Federal dos Vales do Jequitinhonha e Mucuri, Rod. MGT 367, Km 583, Alto Jacuba, CEP 39100-000, Diamantina (MG), Brasil.silviculturaufvjm@yahoo.com.br/nogueirags@yahoo.com.br

3 Engenheiro Agrônomo, Dr., Professor Associado do Departamento de Solos, Universidade Federal de Viçosa, Av. Peter Henry Rolfs, s/n, CEP 36570-000, Viçosa (MG), Brasil. julio_n2003@yahoo.com.br

4 Engenheira Florestal, Dra ${ }^{\mathrm{a}}$., Programa de Pós-Graduação em Ciência Florestal, Universidade Federal dos Vales do Jequitinhonha e Mucuri, Rod. MGT 367, Km 583, Alto Jacuba, CEP 39100-000, Diamantina (MG), Brasil. penidotma@gmail.com 
make the cubage and quantify the dry bark and wood per experimental plot, totaling 15 trees. The sampletrees were weighed in the field and subsamples of bark and wood were collected along the stem to form a composite sample per tree. Also removed was a single sample of each component obtained with the aid of a chisel and hammer in DBH in the same sample-trees. The samples were dried at $65^{\circ} \mathrm{C}$ until constant weight. The material was ground and subjected chemical analysis. Adjusted regression models and application of ANN to estimation of $\mathrm{CBU}_{\text {Trunk }}$ from the $\mathrm{CBU}_{\mathrm{DBH} \text { Bark }}$ and $\mathrm{CBU}_{\mathrm{DBH} \text { wood }}$. The $\mathrm{ANN}$ had a higher accuracy and reliability of the regression. Modeling by artificial neural networks using only sample in the DBH region proved to be adequate for estimating the coefficient of biological use of stem.

Keywords: CBU; ANN; non-destructive sampling; planting density.

\section{INTRODUÇÃO}

A produtividade de uma floresta pode ser influenciada pela fertilização, principalmente, em condições tropicais que possui solos muito intemperizados. A definição da quantidade de nutrientes aplicada pode ser realizada por diferentes métodos. Um ponto crítico na definição de fertilizações pauta-se na quantificação dos nutrientes que são exportados do sítio pela colheita, pois, para manter um sistema sustentável, o nutriente exportado deverá ser reposto. A relação entre produção de biomassa e conteúdo de nutrientes contidos nesta é bem conhecida. Segundo Santana et al. (2008), a distribuição relativa de macronutrientes e de biomassa na parte aérea de eucalipto ao longo dos anos aumenta linear e proporcionalmente.

A reposição de nutrientes exportados pela colheita poderá variar em função da intensidade de uso do solo, dos componentes da biomassa que são colhidos e pela interação dos fatores que afetam a produtividade como a disponibilidade da água, energia radiante, temperatura e gás carbônico (ALMEIDA et al., 2007; COSTA et al., 2009; MENDES et al., 2010). A adoção de práticas silviculturais pode ser diferenciada entre materiais genéticos diante da definição da sua exigência e tolerância ao deficit de nutrientes.

A eficiência de utilização de nutriente pode ser definida como quantidade de matéria seca produzida por grama do nutriente ou o inverso da concentração do nutriente nos tecidos (CHAPIN, 1980), ou ainda, como o Coeficiente de Utilização Biológico (CUB) dos nutrientes. O CUB é uma medida ecológica que integra uma variedade de processos fisiológicos, bem como, a forma em que os nutrientes absorvidos pelas plantas são geralmente usados para a produção de biomassa (ALONGI; CLOUGH; ROBERTSON, 2005), podendo ser usado para auxiliar a seleção de materiais genéticos indicados em diferentes condições edafoclimáticas e para a recomendação de fertilizantes (BARROS et al., 1986; 1995).

O conhecimento do CUB é importante para seleção de genótipos e indicar o tipo de solo mais adequado para a sua adaptação e crescimento. Conhecendo-se o CUB de um nutriente e a expectativa de produção de biomassa é possível estimar a quantidade de nutrientes necessária para um adequado balanço nutricional do próximo ciclo (SAIDELES et al., 2010), sendo este o método mais utilizado para estimar a reposição de nutrientes em plantações de eucalipto.

Atualmente, essa eficiência é obtida abatendo-se árvores-amostras, quantificando a matéria seca e realizando análises químicas de nutrientes em amostras compostas dos seus componentes. Após a fase destrutiva calcula-se o CUB e a partir de então este valor é utilizado para estimar a demanda de nutrientes, pois pelo inventário florestal é possível obter estimativas precisas de biomassa. Entretanto, podem ocorrer variações na eficiência para um mesmo material genético em função das condições edafoclimáticas (SANTANA; BARROS; NEVES, 2002) exigindo constante aferição do CUB. Considerando a escala operacional das grandes empresas florestais, esta aferição é muito importante para obter adequada produção e otimizar a aplicação de fertilizantes. $O$ custo da amostragem destrutiva sempre é superior ao que se pode obter por processos não destrutivos e este aumenta à medida que se amplia a área a ser amostrada.

$\mathrm{Na}$ busca por novas opções para caracterização eficiente, simples e segura das propriedades químicas do vegetal, destacam-se as Amostragens Não Destrutivas (AND). Nestas, as informações sobre o material de interesse são obtidas por medidas indiretas, sendo versátil para se adequar a uma rotina adotada operacionalmente, reduzindo o volume de trabalho, tempo e custo. A obtenção do CUB empregando-se apenas uma amostra de determinada posição na árvore pode não ser representativa, visto que, o teor de nutrientes pode variar ao longo do fuste das árvores conforme mobilidade de redistribuição característica de cada nutriente (SAIDELES et al., 2010). Entretanto, essa diferença pode ser corrigida parametrizando

Ci. Fl., v. 28, n. 2, abr .- jun., 2018 
através da associação da AND com métodos matemáticos e, também, validada pelo método tradicional destrutivo.

Existem diversas ferramentas de natureza estatística que podem ser adotadas para auxiliar no processamento de dados oriundos da AND, dentre as mais empregadas estão a regressão e a interpolação. Embora a estimação por regressão permita a determinação de uma equação que expresse o comportamento de uma dada variável dependente com menos complexidade e fácil interpretação, pode haver situações que estas são incapazes de denotar esse desempenho pela falta de qualidade no ajustamento ou ausência do mesmo.

A inteligência artificial é uma técnica que permite análises flexíveis e obtenção de estimativas confiáveis. Seu uso é crescente e proporciona adequados resultados na Ciência Florestal como, por exemplo, na estimação de volume, altura de árvores e na modelagem do crescimento e produção florestal (GORGENS et al., 2009; BINOTI, 2010).

As Redes Neurais Artificiais (RNA, Artificial Neural Network), ou conexionismo, são modelos computacionais que simulam grosseiramente a estrutura, o processamento de informações e a aquisição de conhecimento do cérebro humano e sistema nervoso, apresentando uma memória associativa e distribuída capaz de estabelecer relações entre variáveis independentes para estimar variáveis dependentes (COELHO; SILVA; PROTIL, 2007). Matematicamente, é um sistema massivo e paralelo, cujas unidades de processamento simples são os neurônios artificiais, dispostos em uma ou mais camadas e interligados entre si com ponderações ajustáveis por um grande número de conexões (GORGENS et al., 2009; BULLINÁRIA, 2011). As RNA possuem as seguintes características: analogia neurobiológica, mapeamento de entrada e saída, tolerância a falhas e ruídos, adaptabilidade dos pesos das conexões às modificações do ambiente e capacidade de generalizar o conhecimento assimilado por aprendizagem para um conjunto de dados desconhecidos (BINOTI, 2010).

Conforme exposto, a AND permite analisar um maior número de informações e estabelecer critérios práticos de caracterização e classificação do material vegetal com uma dada precisão, cuja associação com a técnica de redes neurais artificiais pode ser uma alternativa potencial em substituição às equações de regressão e aos métodos tradicionais de interpolação, conforme descrito por Silva e Cecílio (2010). Portanto, o presente trabalho objetivou avaliar a eficiência da RNA e da amostragem não destrutiva para estimar a eficiência de uso de nutrientes no tronco.

\section{MATERIAIS E MÉTODOS}

O estudo foi conduzido a $17^{\circ} 50^{\prime}$ de latitude Sul e 42 $49^{\prime}$ de longitude Oeste em área da Aperam Bioenergia, antiga ACESITA Energética, no município de Itamarandiba-MG. O clima predominante na região é do tipo Cwa, segundo a classificação de Köppen, com verões quentes e chuvosos e invernos amenos e secos com estação seca bem definida de abril a setembro e deficit hídrico mensal de 30 a $50 \mathrm{~mm}$ (INSTITUTO NACIONAL DE METEOROLOGIA, 2010) e com médias anuais de temperatura e precipitação pluviométrica de $20^{\circ} \mathrm{C}$ e $1160 \mathrm{~mm}$, respectivamente (PULROLNIK et al., 2009).

O experimento foi instalado em dezembro de 2002, utilizando-se um híbrido de Eucalyptus grandis W. Hill ex Maiden x Eucalyptus camaldulensis Dehnh sobre Latossolo Vermelho-Amarelo em relevo plano a $1097 \mathrm{~m}$ de altitude. Adotou-se o delineamento em blocos ao acaso, com três blocos, sendo estudado o efeito de cinco tratamentos constituídos pelos seguintes espaçamentos de plantio: T1 - 3,0 $\mathrm{m}$ x 0,5 m; T2 $3,0 \mathrm{~m} \times 1,0 \mathrm{~m} ; \mathrm{T} 3-3,0 \mathrm{~m} \times 1,5 \mathrm{~m} ; \mathrm{T} 4-3,0 \mathrm{~m} \times 2,0 \mathrm{~m}$ e T5-3,0 $\mathrm{m} \times 3,0 \mathrm{~m}$, sendo $3 \mathrm{~m}$ a distância fixa entre linhas de plantio. Em cada tratamento foram estabelecidas seis linhas de plantio com 28 árvores, totalizando 168 indivíduos, dos quais 48 foram mensurados, por ter sido adotada a bordadura dupla.

Aos oito anos de idade mensurou-se o diâmetro a $1,30 \mathrm{~m}$ de altura do solo $(D A P)$ e altura total $(H t)$ de todas as árvores. Uma árvore-amostra, árvore com diâmetro médio quadrático, foi abatida para realizar a cubagem rigorosa empregando-se o método de Smalian e para quantificar a matéria seca de casca e lenho por unidade experimental, totalizando 15 árvores. As árvores-amostras foram pesadas no campo e subamostras de casca e lenho foram coletadas, de $50 \mathrm{em} 50 \mathrm{~cm}$, ao longo do fuste para compor uma amostra composta por árvore. Também foi retirada uma amostra simples de cada componente obtidas com auxílio de um formão e martelo no $D A P$ nas mesmas árvores-amostras. As dimensões da casca foram de $10,0 \mathrm{~cm}$ x 10,0 cm e 
do lenho de 5,0 cm x 10,0 cm, cujo comprimento foi no sentido vertical, e de, aproximadamente, $2,5 \mathrm{~cm}$ de profundidade interiorizando no lenho. As amostras foram secas a $65^{\circ} \mathrm{C}$ até peso constante em estufa com circulação forçada de ar. $\mathrm{O}$ material vegetal foi moído e submetido à digestão nítrico-perclórica para realizar a análise química de macronutrientes. Os teores de $\mathrm{P}$ foram determinados por colorimetria, de $\mathrm{K}$ por fotometria de emissão de chama, de S por turbidimetria, Ca e Mg por espectrofotometria de absorção atômica. $\mathrm{O} \mathrm{N}$ total foi determinado pelo método Kjeldhal, após digestão sulfúrica.

O coeficiente de utilização biológico do tronco foi calculado pela relação kg matéria seca por $\mathrm{kg}$ de nutrientes e foi denominado "CUB ${ }_{\text {Tronco }}$ " para cada macronutriente. Como o CUB pode ser obtido pelo inverso da concentração do nutriente, foi estimado utilizando-se o resultado analítico obtido pela amostragem pontual de casca e lenho no $D A P$. Estes dados foram utilizados para estimar o $\mathrm{CUB}_{\text {Tronco }}$ pelo seguinte modelo:

$$
C U B_{\text {Tronco }_{x}}=\beta_{0}+\beta_{1} C U B_{\text {DAPCasca }_{x}}+\beta_{2} C U B_{\text {DAPLenho }_{x}}+\varepsilon,
$$

Em que: $x$ = nutriente $(\mathrm{N}, \mathrm{P}, \mathrm{K}, \mathrm{Ca}, \mathrm{Mg}, \mathrm{S})$; = erro aleatório.

Em função da possível falta de ajuste pela regressão quando se relaciona um ponto do tronco em relação à amostragem por toda a sua extensão, incorporaram-se mais variáveis independentes para estimar o CUB ${ }_{\text {Tronco }}$ pelo método Stepwise backward. Os inputs analisados foram assim definidos: CUB no DAP para a casca e lenho, $D A P$ sem casca $_{(\mathrm{cm})}\left(D A P_{s c}\right)$, espessura da casca ${ }_{(\mathrm{cm})}, D A P_{s c} / D A P$, espessura da casca/DAP, $D A P_{(\mathrm{cm})}$ e $H t_{(\mathrm{m})}$

Almejando-se obter um modelo generalista para o CUB do tronco, os macronutrientes foram agrupados em uma única variável denominada NID (nutrients identification) e assim categorizados $\mathrm{N}-1 ; \mathrm{P}$ $-2 ; \mathrm{K}-3 ; \mathrm{Ca}-4 ; \mathrm{Mg}-5$ e $\mathrm{S}-6$. É importante salientar o uso restrito a este trabalho das equações geradas pelos modelos 2 e 3, cuja finalidade foi comparativa do desempenho das redes neurais artificiais com a regressão de forma direta e que integre os macronutrientes analisados em um único modelo estatístico:

$$
\begin{aligned}
& \text { Modelo } 2 \text { (GT): } C U B_{\text {Tronco }_{x}}=\beta_{0}+\beta_{1} C U B_{\text {DAPCasca }_{x}}+\beta_{2} \text { CUB } \text { DAPLenho }_{x}+\beta_{3} N I D_{x}+\varepsilon \text {, } \\
& \text { Modelo } 3 \text { (GC): } C U B_{\text {Tronco }_{x}}=\beta_{0}+\beta_{1} C U_{\text {DAPCasca }_{x}}+\beta_{2} \text { NID }_{x}+\varepsilon \text {, }
\end{aligned}
$$

Em que: $x$ = nutriente $(\mathrm{N}, \mathrm{P}, \mathrm{K}, \mathrm{Ca}, \mathrm{Mg}, \mathrm{S})$; = erro aleatório.

Estimaram-se os CUB para cada modelo pelo método dos mínimos quadrados utilizando o procedimento iterativo Levenberg-Marquardt e por redes neurais artificiais (RNA).

$\mathrm{O}$ treinamento de uma rede neural artificial, também denominado aprendizagem, consiste no ajuste dos parâmetros da rede (pesos e Bias) através de um algoritmo de aprendizagem. Neste processo, os dados de treinamento (conjunto de exemplos) são apresentados a uma arquitetura preestabelecida, ou seja, um determinado número de arranjos de neurônios em camadas. E o algoritmo de treinamento extrai características a fim de representar a informação fornecida e desempenhar uma determinada tarefa. As variáveis utilizadas como entrada das RNA para estimação dos CUB por macronutriente foram numéricas e categórica, conforme modelos 1,2 e 3.

Como possível alternativa ao método de regressão na AND, foram utilizadas redes anteroalimentadas (feedforward), treinadas por meio do algoritmo da retropropagação do erro (backpropagation), ou seja, durante o treinamento da rede foram realizados cálculos a partir da camada de entrada da rede para a de saída e o erro propagado para camadas anteriores. Em todos os pré-processamentos foi realizada a normalização e equalização dos dados visando a uma maior sensibilidade da rede à variação dos mesmos e captar melhor seu comportamento. Os dados foram divididos em grupos de calibração (60\% das amostras), validação (20\%) e teste (20\%), utilizando o método randômico de amostragem.

Foram treinadas 800 RNA do tipo Multilayer Perceptron (MLP): 600 para estimar o CUB Tronco $_{3}$ conforme modelo 1 (100 para cada macronutriente) e 100 para cada modelo restante (modelos 2 e 3 ). Destas foram selecionadas duas com base nos desvios dos valores estimados e observados, sendo, portanto, selecionadas 16 redes para o estudo. A escolha do tipo MLP está relacionada à atribuição de uma maior complexidade das RNA face ao maior número de entradas, o que aumenta o número de parâmetros ajustados 
conforme Braga, Carvalho e Ludermir (2007). A definição da arquitetura das redes, ou seja, número de camadas e o número de neurônios por camada foi otimizada pela ferramenta Intelligent Problem Solver (IPS) do software Statistica 7.0 (STATSOFT, 2007).

A avaliação da acurácia e precisão das equações ajustadas e do resultado do treinamento das redes neurais artificiais foram realizadas por meio do erro $_{\%}$, teste de $\mathrm{RMSE}_{\%}$, teste de $\mathrm{Bias}_{\%}$ e análise de resíduos percentuais. As estimativas das técnicas estatísticas relacionadas à regressão e das RNA foram comparadas por meio do teste $t$ pareado a $5 \%$ de probabilidade com os valores observados, conforme Gorgens et al. (2009). O erro foi assim definido erro $_{\%}=((\hat{y}-y) / y) 100$, enquanto que a raiz do quadrado médio do erro $\left(\mathrm{RMSE}_{\%}\right)$ e a tendenciosidade $\left(\right.$ Bias $_{\%}$ ) foram determinadas segundo Mabvurira e Miina (2002): $R M S E_{\%}=100\left(\sqrt{\sum\left(y_{i}-\hat{y}_{i}\right)^{2} /(n-1)}\right) /\left(\sum \hat{y}_{i} / n\right)$ e $B_{i a S_{\%}}=100\left(\left(\sum\left(y_{i}-\hat{y}_{i}\right)\right) / n\right) /\left(\sum \hat{y}_{i} / n\right), \mathrm{e}, \quad \mathrm{em}$ que $y_{i}$ e $\hat{y}_{i}$ são os valores observados e preditos, respectivamente.

Os ajustes dos modelos de regressão e treinamento das RNA foram realizados com auxílio do software Statistica 7.0 (STATSOFT, 2007).

\section{RESULTADOS E DISCUSSÃO}

Os coeficientes de determinação das equações ficaram próximos à unidade e os parâmetros associados a todas variáveis independentes apresentaram elevada significância estatística (Tabela 1). Entre as variáveis avaliadas pela Stepwise, a relação diâmetro do lenho com o $D A P$ foi a melhor para as estimativas dos CUB individuais para $\mathrm{N}, \mathrm{P}, \mathrm{K}$ e Ca. Para o $\mathrm{Mg}$ foi a relação espessura da casca com $D A P$ e para o $\mathrm{S}$ mais de uma variável explicativa. A variável categórica para as equações generalistas mostrou-se eficiente porque apresentou alta significância. Verificaram-se melhorias na precisão estatística ao incorporar entradas dendrométricas no modelo de estimação do CUB na região do tronco, haja vista que os maiores coeficientes de determinação foram observados para as equações específicas por macronutriente.

TABELA 1: Equações para estimar o $\mathrm{CUB}_{\text {Tronco }}$ para macronutrientes.

TABLE 1: Equations to estimate $\mathrm{CBU}_{\text {Trunk }}$ for macronutrients.

\begin{tabular}{|c|c|c|c|}
\hline & $\mathrm{n}$ & Equações ajustadas & $\bar{R}^{2}$ \\
\hline $\mathrm{N}$ & 15 & $C U B_{\text {Tronco }}=929,67^{* *}\left(D A P_{s c} / D A P\right)$ & 0,992 \\
\hline $\mathrm{P}$ & 15 & $C U B_{\text {Tronco }}=-74125,19^{*}+86851,52^{*}\left(D A P_{S C} / D A P\right)$ & 0,967 \\
\hline $\mathrm{K}$ & 15 & $C U B_{\text {Tronco }}=902,01^{* *}\left(D A P_{S c} / D A P\right)$ & 0,968 \\
\hline $\mathrm{Ca}$ & 15 & $C U B_{\text {Tronco }}=733,50^{* *}\left(D A P_{s c} / D A P\right)$ & 0,968 \\
\hline $\mathrm{Mg}$ & 15 & $C U B_{\text {Tronco }}=8003,18^{* *}-54974,87^{* *}($ espessura da casca $/ D A P)$ & 0,980 \\
\hline $\mathrm{S}$ & 15 & $C U B_{\text {Tronco }}=0,74^{* *} C U B_{\text {DAPLenho }}+192,46^{* *} H t-338,44^{* *} D A P$ & 0,989 \\
\hline GT & 90 & $C U B_{\text {Tronco }_{x}}=0,24^{* *} C U B_{\text {DAPLenho }_{x}}+0,67^{* *}$ CUB $B_{\text {DAPCasca }_{x}}+158,21^{* *}$ Nid $_{x}$ & 0,946 \\
\hline GC & 90 & $\operatorname{CUB}_{\text {Tronco }_{x}}=1,71^{* *}$ CUB $_{\text {DAPCasca }_{x}}+219,07^{* *} \operatorname{Nid}_{x}$ & 0,875 \\
\hline
\end{tabular}

Em que: $\mathrm{GT}=$ Modelo 2; $\mathrm{GC}=$ Modelo 3; $\mathrm{n}=$ número de observações; $\mathrm{x}=\mathrm{N}, \mathrm{P}, \mathrm{K}, \mathrm{Ca}, \mathrm{Mg}$ ou S; ** = significativo a $1 \% ; *$ significativo a $5 \% ; \mathrm{R}^{\wedge} 2$ = coeficiente de determinação corrigido. $\mathrm{N}, \mathrm{P}, \mathrm{K}, \mathrm{Ca}, \mathrm{Mg}, \mathrm{S}$ foram obtidos pelo Modelo 1/Stepwise. Espessura de casca; DAP e DAPsc expressos em $\mathrm{cm}$. CUB expresso em $\mathrm{kg}$ de biomassa $\mathrm{kg}$ de nutriente-1; CUB $=$ Coeficiente de utilização biológico. 
A semelhança dos dados estimados e observados pelas regressões foi evidenciada pela ausência de significância estatística no teste $t$ pareado (Tabela 2). As equações para estimação do $\mathrm{CUB}_{\text {Tronco }}$ do $\mathrm{N}, \mathrm{Mg}$ e $\mathrm{S}$ apresentaram os menores desvios expressos pela $\mathrm{RMSE}_{\%}$, tendenciosidades e erros relativos médios. A utilização da regressão como ferramenta estatística para criar uma equação generalista para todos os macronutrientes categorizados não apresentou adequada acurácia e precisão (GT e GC), apesar de ter apresentado baixo Bias $_{\%}$. A precisão das equações para estimação dos CUB (Tabela 2) não foi comprovada pela análise gráfica, pois a maioria foi heterocedástica (Figura 1).

TABELA 2: Precisão das equações obtidas para os CUB do tronco.

TABLE 2: Equation precisions obtained for CBUs in the trun

\begin{tabular}{cccccccc}
\hline \multirow{2}{*}{ CUB } & \multirow{2}{*}{ RMSE $_{\%}$} & Bias $\%$ & \multicolumn{3}{c}{ Erros Relativos (\%) } & Teste $t$ \\
\cline { 5 - 7 } & & & Máximo & Médio & Mínimo & $p$ \\
\hline $\mathrm{N}$ & 8,40 & 0,00 & 14,46 & 0,66 & $-12,44$ & 0,9990 \\
$\mathrm{P}$ & 18,60 & 0,00 & 38,36 & 3,12 & $-26,98$ & 1,0000 \\
$\mathrm{~K}$ & 18,21 & $-0,09$ & 60,33 & 3,74 & $-24,43$ & 0,9857 \\
$\mathrm{Ca}$ & 18,20 & $-0,08$ & 50,28 & 3,54 & $-24,20$ & 0,9870 \\
$\mathrm{Mg}$ & 14,33 & 0,00 & 49,92 & 2,27 & $-22,69$ & 1,0000 \\
$\mathrm{~S}$ & 10,58 & 0,43 & 14,22 & $-0,55$ & $-19,92$ & 0,8764 \\
$\mathrm{GT}$ & 31,05 & $-1,08$ & 165,84 & 19,28 & $-43,26$ & 0,7413 \\
$\mathrm{GC}$ & 49,05 & 2,06 & 159,69 & 19,51 & $-67,70$ & 0,6908 \\
\hline
\end{tabular}

Em que: $\mathrm{ns}=p>0,05$ no teste $t$ pareado; $\mathrm{GT}=$ Modelo 2; $\mathrm{GC}=$ Modelo 3; RMSE $=$ Root mean square error (raiz do quadrado médio do erro); e Bias = tendenciosidade.

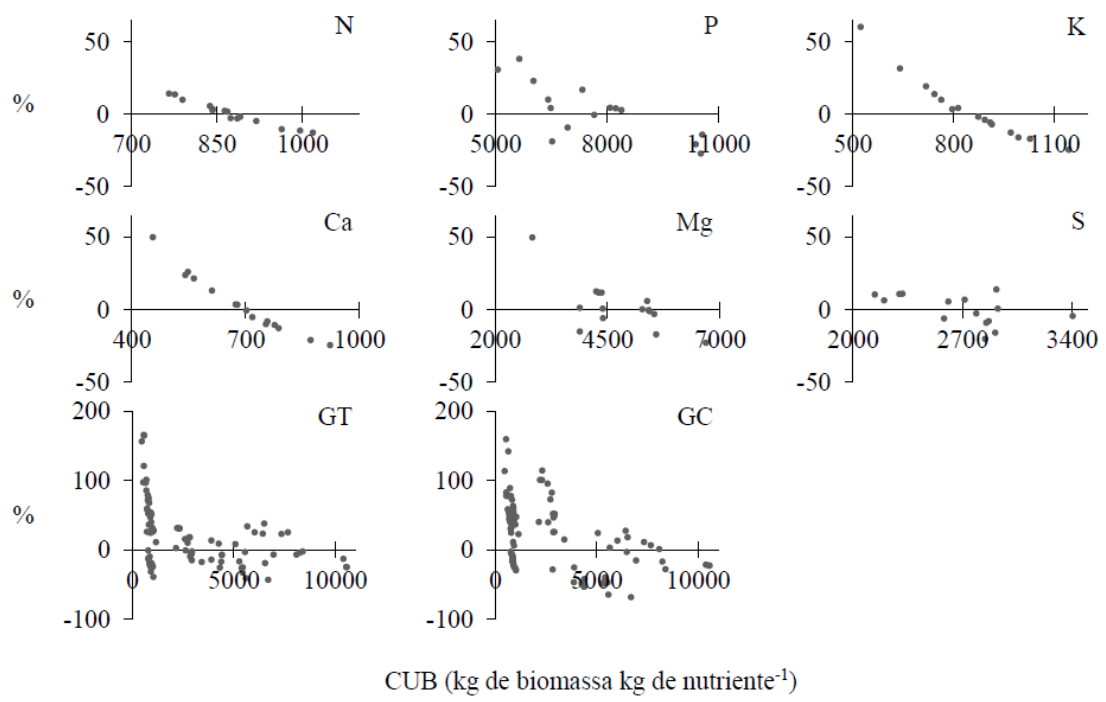

FIGURA 1: Representação da distribuição dos resíduos percentuais (eixos y) em função dos CUB no tronco (eixos $\mathrm{x}, \mathrm{kg}$ de biomassa $\mathrm{kg}$ de nutriente ${ }^{-1}$ ) pelas regressões.

FIGURE 1: Representation of residuals distribution ( $\mathrm{y}$ axis) as a function of $\mathrm{CBU}$ in the trunk ( $\mathrm{x}$ axis, $\mathrm{kg}$ biomass $\mathrm{kg}$ of nutrient ${ }^{-1}$ ) by regressions.

A maioria das redes apresentou funções de ativação de base não linear nas camadas intermediárias e de saída (Tabela 3). Maior complexidade foi observada para as redes generalistas que apresentaram mais neurônios nas camadas intermediárias. As amplitudes de variação do $\mathrm{RMSE}_{\%}$ entre as fases de treino, teste e validação observadas nas redes por nutriente foram muito superiores às das redes generalistas (Tabela 4). Diante da semelhança observada entre os valores de RMSE ${ }_{\%}$, Bias $\%$ e Erros Relativos (\%) dentro de um mesmo tipo de rede, a escolha da melhor rede baseou-se nas probabilidades do teste $t$. Estas probabilidades 
para as redes generalistas e por nutriente apresentaram semelhança entre si superior a 70\% para GC, $\mathrm{P}$ e $\mathrm{Mg}$, consequentemente, procedeu-se a análise gráfica destas (Figura 2). Para o N, K, Ca, S e GT optaramse apenas pela análise gráfica da melhor rede, pois as RNA N2, K1, Ca1, S2 e GT2 apresentaram uma probabilidade inferior a $70 \%$, comparativamente a sua correspondente. As estimativas do CUB Tronco $_{\text {obtidas }}$ pelas RNA comparativamente às das regressões foram mais precisas (Tabelas 2 e 4), além da tendência à homocedasticidade (Figura 2).

TABELA 3: Características das redes neurais artificiais (RNA) selecionadas para projetar o CUB $_{\text {Tronco }}$ dos macronutrientes.

TABLE 3: Characteristics of artificial neural networks (ANN) selected to project the $\mathrm{CBU}_{\text {Trunk }}$ of macronutrient.

\begin{tabular}{|c|c|c|c|c|c|c|c|}
\hline \multirow{2}{*}{ RNA } & \multirow{2}{*}{$\mathrm{n}$} & \multirow{2}{*}{ TIPO } & \multirow{2}{*}{ Arquitetura } & \multicolumn{2}{|c|}{----- Entradas ----- } & \multicolumn{2}{|c|}{-- Função de Ativação -- } \\
\hline & & & & Numéricas & Categórica & Intermediária & Saída \\
\hline N1 & MLP & $2-8-1$ & 15 & CUB $_{\text {DAP Casca }}, \mathrm{CUB}_{\text {DAP Lenho }}$ & & Tangencial & Identidade \\
\hline $\mathrm{N} 2$ & MLP & $2-6-1$ & 15 & $\mathrm{CUB}_{\text {DAP Casca }}, \mathrm{CUB}_{\text {DAP Lenho }}$ & & Tangencial & Identidade \\
\hline $\mathrm{P} 1$ & MLP & $2-9-1$ & 15 & CUB $_{\text {DAP Casca }}, \mathrm{CUB}_{\text {DAP Lenho }}$ & & Logística & Logística \\
\hline $\mathrm{P} 2$ & MLP & $2-5-1$ & 15 & CUB $_{\text {DAP Casca }}$, CUB $_{\text {DAP Lenho }}$ & & Logística & Logística \\
\hline $\mathrm{K} 1$ & MLP & $2-3-1$ & 15 & $\mathrm{CUB}_{\text {DAP Casca }}, \mathrm{CUB}_{\mathrm{DAP} \text { Lenho }}$ & & Logística & Logística \\
\hline $\mathrm{K} 2$ & MLP & $2-3-1$ & 15 & CUB $_{\text {DAP Casca }}, \mathrm{CUB}_{\text {DAP Lenho }}$ & & Tangencial & Logística \\
\hline $\mathrm{Ca} 1$ & MLP & $2-9-1$ & 15 & CUB $_{\text {DAP Casca }}, \mathrm{CUB}_{\text {DAP Lenho }}$ & & Tangencial & Exponencial \\
\hline $\mathrm{Ca} 2$ & MLP & $2-7-1$ & 15 & $\mathrm{CUB}_{\text {DAP Casca }}, \mathrm{CUB}_{\mathrm{DAP} \text { Lenho }}$ & & Tangencial & Exponencial \\
\hline $\mathrm{Mg} 1$ & MLP & $2-9-1$ & 15 & $\mathrm{CUB}_{\text {DAP Casca }}, \mathrm{CUB}_{\mathrm{DAP} \text { Lenho }}$ & & Exponencial & Logística \\
\hline $\mathrm{Mg} 2$ & MLP & $2-6-1$ & 15 & $\mathrm{CUB}_{\text {DAP Casca }}, \mathrm{CUB}_{\mathrm{DAP} \text { Lenho }}$ & & Logística & Logística \\
\hline S1 & MLP & $2-9-1$ & 15 & $\mathrm{CUB}_{\text {DAP Casca }}, \mathrm{CUB}_{\mathrm{DAP} \text { Lenho }}$ & & Exponencial & Tangencial \\
\hline $\mathrm{S} 2$ & MLP & $2-9-1$ & 15 & CUB $_{\text {DAP Casca }}, \mathrm{CUB}_{\text {DAP Lenho }}$ & & Tangencial & Tangencial \\
\hline GT1 & MLP & $8-7-1$ & 90 & $\mathrm{CUB}_{\text {DAP Casca }}, \mathrm{CUB}_{\text {DAP Lenho }}$ & Nid & Exponencial & Tangencial \\
\hline GT2 & MLP & $8-10-1$ & 90 & $\mathrm{CUB}_{\text {DAP Casca }}, \mathrm{CUB}_{\text {DAP Lenho }}$ & Nid & Identidade & Identidade \\
\hline $\mathrm{GC} 1$ & MLP & $7-12-1$ & 90 & $\mathrm{CUB}_{\text {DAP Casca }}$ & Nid & Tangencial & Identidade \\
\hline $\mathrm{GC} 2$ & MLP & $7-12-1$ & 90 & $\mathrm{CUB}_{\text {DAP Casca }}$ & Nid & Logística & Identidade \\
\hline
\end{tabular}

Em que: $\mathrm{GT}=$ Modelo 2; GC $=$ Modelo 3; $\mathrm{n}=$ número de observações; $\mathrm{MLP}=$ Multilayer Perceptron (múltiplas camadas); CUBDAP Casca = coeficiente de utilização biológico no DAP para a casca; CUBDAP Lenho = coeficiente de utilização biológico no DAP para o lenho; e Nid = nutrients identification (identificação de nutrientes). CUB expresso em $\mathrm{kg}$ de biomassa $\mathrm{kg}$ de nutriente-1.

TABELA 4: Precisão das redes neurais artificiais (RNA).

TABLE 4: Precision of artificial neural networks (ANN).

\begin{tabular}{|c|c|c|c|c|c|c|c|}
\hline \multirow{2}{*}{ RNA } & \multirow{2}{*}{ Fases } & \multirow{2}{*}{$\mathrm{RMSE}_{\%}$} & \multirow{2}{*}{ 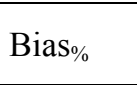 } & \multicolumn{3}{|c|}{ Erros Relativos (\%) } & \multirow{2}{*}{$\begin{array}{c}\text { Teste } t \\
p\end{array}$} \\
\hline & & & & Máximo & Médio & Mínimo & \\
\hline \multirow[t]{3}{*}{ N1 } & Calibração & 4,37 & 0,39 & 5,39 & $-0,24$ & $-8,13$ & \\
\hline & Teste & 6,49 & 2,66 & 3,14 & $-2,42$ & $-7,15$ & 0,2572 \\
\hline & Validação & 2,29 & 3,66 & 3,74 & $-3,5$ & $-8,57$ & \\
\hline \multirow[t]{3}{*}{ N2 } & Calibração & 2,88 & $-0,01$ & 4,67 & 0,10 & $-6,46$ & \\
\hline & Teste & 5,54 & 2,97 & 1,59 & $-2,93$ & $-6,90$ & 0,086 \\
\hline & Validação & 1,88 & 7,60 & $-2,84$ & $-7,04$ & $-9,22$ & \\
\hline \multirow[t]{3}{*}{$\mathrm{P} 1$} & Calibração & 17,59 & 1,48 & 40,16 & 1,15 & $-18,00$ & \\
\hline & Teste & 25,86 & $-20,59$ & 30,20 & 25,65 & 19,46 & 0,5399 \\
\hline & Validação & 0,10 & 4,86 & 19,42 & $-2,39$ & $-18,59$ & \\
\hline
\end{tabular}


TABELA. 4: Continuação...

TABLE.4: Continued...

\begin{tabular}{|c|c|c|c|c|c|c|c|}
\hline \multirow{2}{*}{ RNA } & \multirow{2}{*}{ Fases } & \multirow[b]{2}{*}{$\mathrm{RMSE}_{\%}$} & \multirow{2}{*}{ Bias\% } & \multicolumn{3}{|c|}{ Erros Relativos (\%) } & \multirow{2}{*}{$\begin{array}{c}\text { Teste } t \\
p \\
\end{array}$} \\
\hline & & & & Máximo & Médio & Mínimo & \\
\hline \multirow[t]{3}{*}{ P1 } & Calibração & 17,59 & 1,48 & 40,16 & 1,15 & $-18,00$ & \\
\hline & Teste & 25,86 & $-20,59$ & 30,20 & 25,65 & 19,46 & 0,5399 \\
\hline & Validação & 0,10 & 4,86 & 19,42 & $-2,39$ & $-18,59$ & \\
\hline \multirow[t]{3}{*}{$\mathrm{P} 2$} & Calibração & 17,98 & 2,72 & 39,07 & $-0,16$ & $-19,16$ & \\
\hline & Teste & 26,86 & $-21,81$ & 30,04 & 27,86 & 26,51 & 0,5327 \\
\hline & Validação & 0,11 & 2,40 & 20,91 & $-0,17$ & $-15,68$ & \\
\hline \multirow[t]{3}{*}{ K1 } & Calibração & 9,45 & $-0,63$ & 22,72 & 2,36 & $-12,91$ & \\
\hline & Teste & 26,54 & $-20,51$ & 37,38 & 26,36 & 13,05 & 0,0258 \\
\hline & Validação & 0,60 & $-17,68$ & 41,34 & 22,66 & 9,58 & \\
\hline \multirow[t]{3}{*}{ K2 } & Calibração & 11,14 & 4,37 & 17,85 & $-3,06$ & $-15,03$ & \\
\hline & Teste & 26,84 & $-20,67$ & 37,90 & 26,62 & 12,67 & 0,1492 \\
\hline & Validação & 0,59 & $-17,70$ & 41,78 & 22,72 & 8,64 & \\
\hline \multirow[t]{3}{*}{ Ca1 } & Calibração & 8,75 & $-1,06$ & 20,01 & 2,01 & $-15,67$ & \\
\hline & Teste & 28,64 & $-9,05$ & 44,93 & 17,84 & $-15,99$ & 0,4551 \\
\hline & Validação & 1,76 & $-0,84$ & 8,30 & 1,46 & $-11,65$ & \\
\hline \multirow[t]{3}{*}{$\mathrm{Ca} 2$} & Calibração & 7,76 & $-0,61$ & 14,20 & 1,46 & $-12,63$ & \\
\hline & Teste & 30,78 & $-7,88$ & 44,09 & 16,91 & $-19,27$ & 0,8221 \\
\hline & Validação & 0,98 & 16,03 & 0,93 & $-13,40$ & $-21,84$ & \\
\hline \multirow{3}{*}{ Mg1 } & Calibração & 11,56 & 2,57 & 10,91 & $-1,43$ & $-19,38$ & \\
\hline & Teste & 16,83 & $-7,15$ & 37,45 & 11,63 & $-4,25$ & 0,6446 \\
\hline & Validação & 0,10 & 8,16 & 18,42 & $-7,31$ & $-30,42$ & \\
\hline \multirow[t]{3}{*}{$\mathrm{Mg} 2$} & Calibração & 11,11 & 1,47 & 14,28 & $-0,37$ & $-18,70$ & \\
\hline & Teste & 21,72 & $-1,27$ & 38,23 & 6,83 & $-12,76$ & 0,6163 \\
\hline & Validação & 0,10 & 6,71 & 19,75 & $-6,04$ & $-30,11$ & \\
\hline \multirow[t]{3}{*}{ S1 } & Calibração & 6,69 & $-0,14$ & 13,23 & 0,61 & $-11,23$ & \\
\hline & Teste & 5,56 & 2,38 & 2,95 & $-2,27$ & $-5,89$ & 0,8547 \\
\hline & Validação & 0,25 & $-4,24$ & 16,96 & 4,44 & $-20,12$ & \\
\hline \multirow[t]{3}{*}{$\mathrm{S} 2$} & Calibração & 8,10 & $-0,73$ & 11,46 & 1,42 & $-13,17$ & \\
\hline & Teste & 9,92 & 7,44 & $-2,77$ & $-6,87$ & $-8,94$ & 0,4833 \\
\hline & Validação & 0,32 & 3,67 & 16,04 & $-3,13$ & $-15,75$ & \\
\hline \multirow[t]{3}{*}{ GT1 } & Calibração & 25,42 & 1,00 & 54,07 & 4,10 & $-30,64$ & \\
\hline & Teste & 21,51 & 0,39 & 55,97 & 0,64 & $-39,49$ & 0,7801 \\
\hline & Validação & 24,71 & $-4,96$ & 85,83 & 8,75 & $-33,56$ & \\
\hline \multirow[t]{3}{*}{ GT2 } & Calibração & 24,32 & $-6,28$ & 49,62 & 3,07 & $-28,43$ & \\
\hline & Teste & 24,78 & 0,03 & 48,57 & 6,25 & $-23,02$ & 0,2833 \\
\hline & Validação & 27,03 & $-6,76$ & 52,91 & 10,87 & $-35,88$ & \\
\hline \multirow[t]{3}{*}{ GC1 } & Calibração & 24,33 & $-0,09$ & 53,90 & 2,25 & $-25,27$ & \\
\hline & Teste & 28,55 & $-6,49$ & 34,47 & 3,87 & $-26,15$ & 0,3041 \\
\hline & Validação & 25,68 & $-5,91$ & 53,26 & 10,14 & $-35,56$ & \\
\hline \multirow[t]{3}{*}{$\mathrm{GC} 2$} & Calibração & 29,95 & $-5,27$ & 57,29 & 2,54 & $-24,46$ & \\
\hline & Teste & 24,33 & 0,30 & 35,54 & 3,07 & $-25,91$ & 0,4073 \\
\hline & Validação & 25,96 & $-5,64$ & 59,13 & 9,51 & $-35,53$ & \\
\hline
\end{tabular}

Em que: ${ }^{\text {ns }}=\mathrm{p}>0,05$ no teste $\mathrm{t}$ pareado; $\mathrm{GT}=$ Modelo 2; $\mathrm{GC}=$ Modelo 3; RMSE $=$ Root mean square error (raiz do quadrado médio do erro); e Bias = tendenciosidade. 


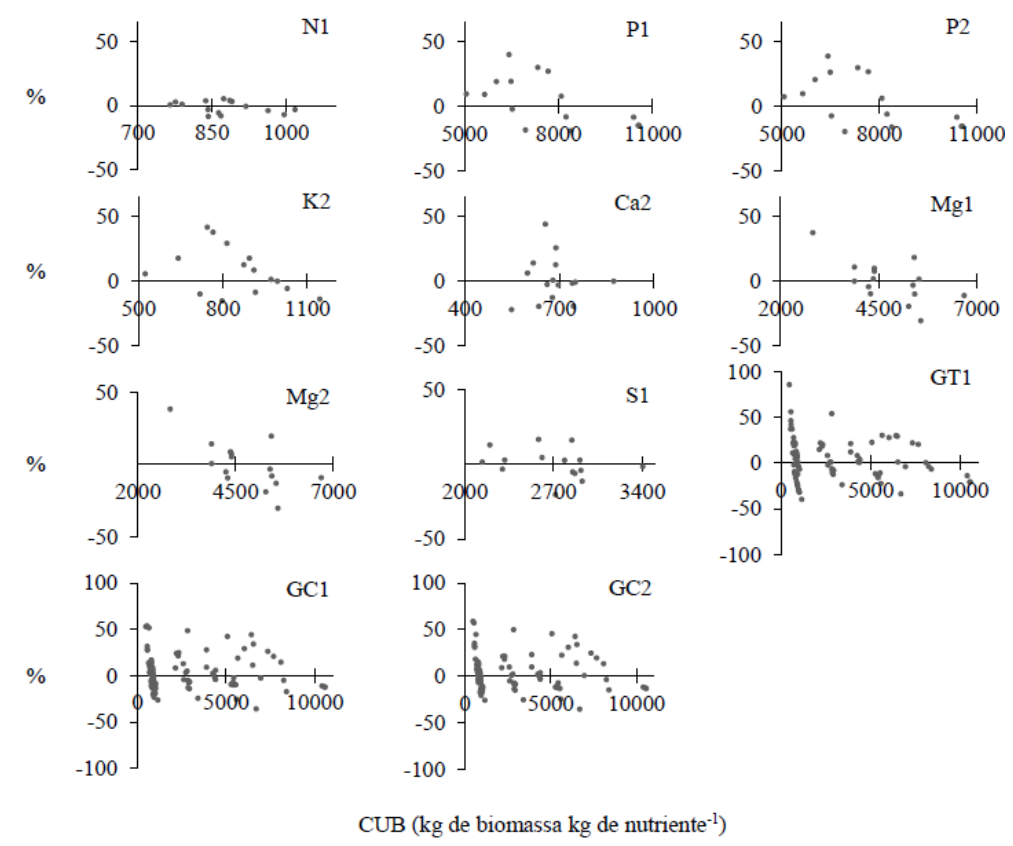

FIGURA 2: Representação da distribuição dos resíduos percentuais (eixos y) em função dos CUB no tronco (eixos $\mathrm{x}, \mathrm{kg}$ de biomassa $\mathrm{kg}$ de nutriente $\mathrm{e}^{-1}$ ) pelas redes.

FIGURE 2: Representation of residual distributions ( $\mathrm{y}$ axis) as a function of $\mathrm{CBU}$ in the trunk ( $\mathrm{x}$ axis, $\mathrm{kg}$ biomass $\mathrm{kg}$ of nutrient ${ }^{-1}$ ) by networks.

A superioridade da inteligência artificial por meio das RNA foi verificada em relação aos algoritmos de regressão (Tabelas 2 e 4; Figuras 1 e 2) para estimar o CUB $_{\text {Tronco. }}$. Além disso, foi precisa na estimação simultânea e generalista do $\mathrm{CUB}_{\text {Tronco }}$ de todos o macronutrientes, baseando-se apenas na amostragem da casca na região do DAP. Salienta-se que a eficiência das RNA já foi comprovada na predição variáveis químicas e físicas do solo para locais não amostrados, análises químicas analíticas e identificação de deficiências nutricionais (SENA et al., 2000; ANGELICO, 2005; SARTIN, 2014). De acordo Haykin (2001), as RNA possibilitam a obtenção de estimativas mais precisas que o ajuste de modelos matemáticos convencionais, fato que a torna atrativa para solução de uma série de problemas. Entretanto, o estabelecimento de relações funcionais entre CUB e atributos do povoamento ainda é incipiente.

A precisão das RNA foi considerada satisfatória, em virtude da complexidade e quantidade de processos biológicos que influenciam o CUB. Trata-se de um coeficiente que pode ser afetado por características morfológicas (relação raiz-parte aérea, eficiência e extensão do sistema radicular) e fisiológicas (taxa fotossintética e a capacidade de manter o metabolismo normal com baixo teor de nutrientes nos tecidos) (NOVAIS et al., 2007). A capacidade das redes oriundas do Modelo 3 (GC) de estabelecer relações funcionais entre variáveis dependentes e independentes não foi prejudicada pela função de ativação do tipo identidade na camada de saída. Foi verificada a utilização de funções não lineares nas camadas intermediárias para a maioria das RNA (Tabela 3). Segundo Braga, Carvalho e Ludermir (2007), esta tendência permite que a composição das funções nas camadas sucessivas tenha capacidade de resolver os problemas de maior ordem no espaço de entrada. Haja vista que a modelagem por RNA não visa ao levantamento de parâmetros físicos do sistema, mas sim, prover um modelo que descreva o seu comportamento. A habilidade da rede em modelar qualquer processo não linear está relacionada ao seu sistema de processamento simples interligado por neurônios artificiais, que aceitam inputs únicos ou múltiplos para produzir uma saída por uma função de transferência (BEHERA; RENE; PARK, 2012).

Embora as redes generalistas tenham apresentado um RMSE\% em torno de 25, o melhor treino e pior validação da rede GC1 (Tabela 3) não implicou em uma memorização excessiva dos dados de treinamento, pois não foram utilizados muitos neurônios na camada intermediária e aplicou-se uma normalização dos dados como heurística. Esta normalização é um recurso muito utilizado no processamento estatístico com RNA visando a uma aproximação da solução ideal dos problemas minimizando os erros (STATSOFT, 2007; 
SOARES et al., 2011). É importante ressaltar que não existe um método generalizado para determinar valores ótimos para o número de camadas intermediárias ou de neurônios na mesma, pois estas ocorrem em função da inteligência esperada. Considera-se-, ainda, que a variância total de ensaios experimentais não está isenta de erros, sendo parte atribuída a fatores controlados de causas conhecidas e outra, a fatores de natureza aleatória.

A capacidade de generalização e conectividade das RNA permitiu que se utilizasse apenas uma rede para realizar a estimação simultânea dos CUB do tronco, demonstrando que pode captar o realismo biológico dos dados. O desempenho das RNA generalistas foi mais conciso e consistente que as construídas por macronutriente, apresentando melhor distribuição das estatísticas de precisão entre as fases de treino, teste e validação (Tabela 4). Isto se deve, provavelmente, ao maior número de observações e representatividade no processamento das redes generalistas.

As redes GC foram construídas com apenas o $\mathrm{CUB}_{\mathrm{DAP} \text { Casca }}$ como variável mensurada em relação à GT1, que também necessita do $\mathrm{CUB}_{\mathrm{DAP} \text { Lenho }}$. Esta diferença possui grande significado prático, pois necessita-se amostrar apenas a casca na região do DAP e não casca e lenho. Consequentemente, o processo de amostragem em campo é muito mais rápido, menos oneroso e reduz à metade o custo analítico, além de ser menos laboriosa pela possibilidade de utilização de equipamentos mais simples e de fácil manuseio, como o facão para coletar a casca. Uma constante aferição nos valores do $\mathrm{CUB}_{\text {Tronco }}$ em condições de campo é necessária porque variações podem ocorrer para um mesmo material genético em função das condições edafoclimáticas (SANTANA; BARROS; NEVES, 2002). Desta forma, um modelo generalista como o obtido pelas redes reduz as atividades operacionais para obtenção do $\mathrm{CUB}_{\text {Tronco }}$.

O CUB é a base da recomendação de fertilizantes e o método não destrutivo proposto pelo presente trabalho forneceu estimativas precisas. Apesar de ser mais complexa que a regressão, a implementação das redes neurais como ferramenta demonstrou ser uma adequada opção para estimar o CUB. Esta é uma ferramenta que carece ser mais bem explorada nas áreas de pesquisa e nutrição florestal.

\section{CONCLUSÃO}

A modelagem por redes neurais artificiais utilizando-se apenas amostra da casca na região do DAP demonstrou ser adequada para a estimativa do coeficiente de utilização biológico do tronco em eucalipto.

\section{AGRADECIMENTOS}

À CAPES, ao CNPq, à Aperam Bioenergia, à UFVJM e à UFV por toda assistência, auxílio financeiro e apoio.

\section{REFERÊNCIAS}

ALMEIDA, A. C. et al. Growth and water balance of Eucalyptus grandis hybrids plantations in Brazil during a rotation for pulp production. Forest Ecology and Management, Amsterdam, v. 251, n. 1-2, p. 10-21, out. 2007.

ALONGI, D. M.; CLOUGH, B. F.; ROBERTSON, A. I. Nutrient use efficiency in arid-zone forests of the mangroves Rhizophora stylosa and Avicennia marina. Aquatic Botany, Amsterdam, v. 82, n. 2, p. 121-131, jun. 2005.

ANGELICO, J. C. Desempenho das redes neurais artificiais na estimativa das variáveis físicas e químicas do solo. 2005. 160 f. Tese (Doutorado em Agronomia) - Universidade Estadual Paulista, Botucatu, 2005.

BARROS, N. F. et al. Classificação nutricional de sítios florestais - Descrição de uma metodologia. Revista Árvore, Viçosa, MG, v. 10, n. 2, p. 112-120, 1986.

BARROS, N. F. et al. Nutricalc 2.0 - Sistema para cálculo del balance nutricional y recomendación de fertilizantes para el cultivo de eucalipto. Bosque, Santiago, v. 16, n. 1, p. 129-131, 1995.

BEHERA, S. K.; RENE, E. R.; PARK, H. S. Neural network modeling of sorption of pharmaceuticals in engineered floodplain filtration system. Expert Systems with Applications, Amsterdam, v. 39, n. 5, 
p. 6052-6060, abr. 2012.

BINOTI, M. L. M. S. Redes neurais artificiais para prognose da produção de povoamentos não desbastados de eucalipto. 2010. 54 f. Dissertação (Mestrado em Ciência Florestal) - Universidade Federal de Viçosa, Viçosa, MG, 2010.

BRAGA, A. P.; CARVALHO, A. P.; LUDERMIR, T. B. Redes neurais artificiais: teoria e aplicações. 2. ed. Rio de Janeiro: LTC, 2007. 226 p.

BULLINÁRIA, J. A. Introduction to Neural Computation. Notas de aula. 2011. Disponível em: <http:// www.cs.bham.ac.uk/ jxb/inc.html>. Acesso em: 8 de nov. 2011.

CHAPIN, F. S. The mineral nutrition of wild plants. Annual Review of Ecology and Systematics, Palo Alto, v. 11, p. 233-260, 1980.

COELHO, L. S.; SILVA, W. V.; PROTIL, R. M. Previsão não-linear dos preços de troncos de eucalipto baseada em uma abordagem neuroevolutiva. Gestão \& Produção, São Carlos, v. 14, n. 1, p. 139-154, jan./ abr. 2007.

COSTA, A. M. et al. Avaliação do risco de anoxia para o cultivo do eucalipto no Rio Grande do Sul utilizando-se levantamento de solos. Scientia Forestalis, Piracicaba, v. 37, n. 84, p. 367-375, dez. 2009.

GORGENS, E. B. et al. Estimação do volume de árvores utilizando redes neurais artificiais. Revista Árvore, Viçosa, mg, v. 33, n. 6, p. 1141-1147, nov./dez. 2009.

HAYKIN, S. Redes Neurais: princípios e prática. 2. ed. Porto Alegre: Bookman, 2001. 900 p.

INSTITUTO NACIONAL DE METEOROLOGIA (Brasil). INMET: Instituto Nacional de Meteorologia. [2010]. Disponível em: <http://www.inmet.gov.br>. Acesso em: 16 out. 2010.

MABVURIRA, D.; MIINA, J. Individual-tree growth and mortality models for Eucalyptus grandis (Hill) Maiden plantations in Zimbabwe. Forest Ecology and Management, Amsterdam, v. 161, n. 1-3, p. 231245, maio 2002.

MENDES, S. C. et al. Absorção e distribuição de nutrientes em plantios comerciais de bambu (Bambusa vulgaris) no nordeste do Brasil. Árvore, Viçosa, MG, v. 34, n. 6, p. 991-999, nov./dez. 2010.

NOVAIS, R. F. et al. Fertilidade do solo. 1. ed. Viçosa, MG: Sociedade Brasileira de Ciência do Solo, 2007. $1017 \mathrm{p}$.

PULROLNIK, K. et al. Estoques de carbono e nitrogênio em frações lábeis e estáveis da matéria orgânica de solos sob eucalipto, pastagem e cerrado no Vale do Jequitinhonha-MG. Revista Brasileira de Ciência do Solo, Viçosa, MG, v. 33, n. 5, p. 1125-1136, set./out. 2009.

SAIDELES, F. L. F. et al. Determinação do ponto de amostragem para a quantificação de macronutrientes em Acacia mearnsii de Wild. Revista Floresta, Curitiba, v. 40, n. 1, p. 49-62, jan./mar. 2010.

SANTANA, R. C. et al. Alocação de nutrientes em plantios de eucalipto no Brasil. Revista Brasileira de Ciência do Solo, Viçosa, MG, v. 32, p. 2723-2733, 2008.

SANTANA, R. C.; BARROS, N. F.; NEVES, J. C. L. Eficiência de utilização de nutrientes e sustentabilidade da produção em procedências de Eucalyptus grandis e Eucalyptus saligna em sítios florestais do estado de São Paulo. Revista Árvore, Viçosa, MG, v. 26, n. 4, p. 447-457, jul./ago. 2002.

SARTIN, M. A. Projeto e implementação de redes neurais artificiais em distintos níveis de abstrações para o reconhecimento de deficiências de diversos macronutrientes e cultivares. 2014. $252 \mathrm{f}$. Tese (Doutorado em Engenharia Elétrica) - Universidade Estadual Paulista, Ilha Solteira, 2014.

SENA, M. M. et al. Avaliação do uso de métodos quimiométricos em análise de solos. Química Nova, São Paulo, v. 23, n. 4, p. 547-556, 2000.

SILVA, K. S.; CECÍLIO. R. A. Uso de redes neurais artificiais para a estimativa das temperaturas do ar médias, máximas e mínimas, mensais e anuais no estado do Espírito Santo. Caminhos de Geografia, Uberlândia, v. 11, n. 34, p. 84-92, jun. 2010.

SOARES, F. A. A. M. N. et al. Recursive diameter prediction and volume calculation of eucalyptus trees using Multilayer Perceptron Networks. Computers and Electronics in Agriculture, Amsterdam, v. 78, n. 1, p. 19-27, ago. 2011.

STATSOFT. Statistica (data analysis software system), version 7. [2007]. Disponível em: $<$ http://www. statsoft.com>. Acesso em: 2007. 